\title{
Trabeculotomy in late onset congenital glaucoma
}

\author{
LEONARD ROTHKOFF, ${ }^{1}$ MICHAEL BLUMENTHAL, ${ }^{1}$ AND BENZION BIEDNER ${ }^{2}$ \\ From the ${ }^{1}$ Eye Institute, Chaim Sheba Medical Center, Tel Hashomer, and the ${ }^{2}$ Soroka Medical Center, \\ Beersheva, Israel
}

SUMMARY All eyes of children above the age of 1 year referred because of glaucoma were treated with trabeculotomy as the primary procedure. The surgery was modified by the excision of a rectangle of tissue in the deep scleral bed under the scleral flap instead of the classical radial incision. This serves to exteriorise Schlemm's canal while thinning the scleral tissue, without, however, entering the anterior chamber. A total of 7 eyes in 5 children between the ages of 1 and 9 years were operated upon. In 6 of the 7 eyes intraocular pressure has remained under $20 \mathrm{mmHg}$ without treatment after follow-up of between 18 months and 4 years. In the seventh eye intraocular pressure was controlled for 2 years but has since required epinephrine drops twice daily for the maintenance of pressure below $20 \mathrm{mmHg}$. In 4 of the 7 eyes flat, diffuse conjunctival filtering blebs are present, but no complications have been encountered. We consider that trabeculotomy may be recommended for children with late-onset congenital glaucoma.

Trabeculotomy has been reported to be a safe, effective procedure for congenital glaucoma (McPherson, 1973), but has been less successful in adult chronic simple glaucoma (Luntz and Livingston, 1977). We wish to report a series of children with late-onset congenital glaucoma first presenting above the age of 1 year and undergoing trabeculotomy as their primary and only procedure. In 7 eyes of 5 children the surgery lowered the intraocular pressure to under $20 \mathrm{mmHg}$ after a follow-up period of between 18 months and 4 years.

\section{Materials and methods}

All children above the age of 1 year referred to the eye clinic because of raised intraocular pressure were included in the study. When medical treatment was unsuccessful or inappropriate, trabeculotomy $a b$ externo was performed as the primary procedure.

Initial intraocular pressures were measured with an applanation tonometer either at the slit lamp for older children or under halothane anaesthesia in younger children. In the latter cases measurements of postoperative pressures were followed by ketamine anaesthesia. Gonioscopy was performed in all patients pre- and postoperatively.

The surgical technique used was a modified form of Harms and Danheim's original method (Harms

Address for reprints: Prof. M. Blumenthal, Eye Institute, Chaim Sheba Medical Center, Tel Hashomer, Israel and Danheim, 1970). A limbal based conjunctival flap is dissected to expose the desired surgical area. A $4 \times 4 \mathrm{~mm}$ lamellar scleral flap hinged on the corneal side is then reflected. At the anterior portion of the exposed scleral bed an additional $2 \times 2 \mathrm{~mm}$ of tissue is excised, care being taken not to enter the anterior chamber. This serves to exteriorise Schlemm's canal while allowing better identification of the anatomical landmarks in the area and facilitating entry into the canal with the trabeculotome of Harms. The scleral flap is closed with two 7-0 silk sutures, and the conjunctival flap securely closed with 7-0 continuous silk sutures.

A total of 7 eyes in 5 children were operated upon and followed-up for a minimum of 18 months.

\section{Results}

A summary is given in Table 1. In all children the intraocular pressure was lowered to below $20 \mathrm{mmHg}$. In Case 5 the pressure was normal for 2 years but has subsequently required twice-daily epinephrine $1 \%$ drops to maintain this control. Four of the 7 eyes had flat, diffuse, filtering blebs; their occurrence could not be correlated with the level of intraocular pressure.

Gonioscopy preoperatively showed what appeared to be sheets of brownish mesoderm of the iris spreading over the ciliary body and trabecular meshwork. Postoperatively a widely clefted trabecular meshwork could be seen in the operated area 
Table 1 Results of trabeculotomy for late onset congenital glaucoma

\begin{tabular}{lllllll}
\hline Case & Eye & $\begin{array}{l}\text { Age at } \\
\text { surgery } \\
\text { (years) }\end{array}$ & $\begin{array}{l}\text { Pressure } \\
\text { before } \\
\text { surgery }\end{array}$ & $\begin{array}{l}\text { Final } \\
\text { pressure }\end{array}$ & Bleb & $\begin{array}{l}\text { Follow-up } \\
\text { (years) }\end{array}$ \\
\hline 1 & OD & 1 & 40 & 18 & No & $1 \frac{1}{2}$ \\
2 & OD & 1 & 35 & 12 & No & 4 \\
3 & OD & 3 & 40 & 10 & Yes & $2 \frac{1}{2}$ \\
& OS & 3 & 35 & 17 & No & $2 \frac{1}{2}$ \\
4 & OD & 7 & 35 & 19 & Yes & 2 \\
& OS & 7 & 30 & 18 & Yes & 2 \\
5 & OS & 9 & 31 & $18 *$ & Yes & 4 \\
\hline
\end{tabular}

*Medical treatment

of the angle. Reflux of blood from the ruptured canal of Schlemm into the anterior chamber was seen in 5 of the 7 eyes.

There were no serious complications. A small hyphaema was present at the end of surgery in all eyes. There was no loss of the anterior chamber at operation in any case. In 1 eye the anterior chamber was shallow postoperatively for 1 week but spontaneously deepened. There have been no postoperative infections of the filtering blebs.

\section{Discussion}

Trabeculotomy, first described by Smith (1960), has been used in an attempt to remove the resistance to aqueous flow across the trabecular meshwork. Its success in adult glaucoma has been limited in comparison to other procedures, but it has been found to be of distinct benefit in congenital glaucoma, working just as well in eyes with cloudy corneas as in those with clear ones (Lunz and Livingstone, 1977).

$80 \%$ of congenital glaucomas are apparent before the age of 1 year (Kolker and Hetherington, 1976). Those cases appearing after this age have variously been classified as infantile or juvenile glaucomas. Our experience justifies their being considered cases of late-onset congenital glaucoma, both because of their gonioscopic appearance and because of their response to treatment. Our excellent results in this series with trabeculotomy as the sole surgical procedure support this view.

We consider that accurate localisation of Schlemm's canal, the key to successful external trabeculotomy, may be made easier by excision of the deep rectangle of scleral tissue, as in our modified procedure. The thinning of the scleral flap may also aid transscleral filtration, as has recently been suggested by in-vitro studies (Shields et al., 1977). On the other hand this thinning of the tissue may have been responsible for our high incidence of filtering conjunctival blebs. The procedure was found to be free of complications, unlike the series reported by Brachet et al. (1972), and the diffuse, shallow blebs have not been responsible for any postoperative infections.

Because of our success in these cases, without complications, we feel that external trabeculotomy can be recommended for children with congenital glaucoma both of early and of late onset.

We thank Mrs Bilha Savell for technical assistance.

\section{References}

Brachet, A., Singer, B., and Dubois-Poulsen, A. (1972). Complications de la trabeculotomie. Annales d'Oculistique, 205, 1203-1213.

Harms, H., and Dannheims, R. (1970). Trabeculotomy results and problems. In Microsurgery in Glaucoma, p. 121 . Edited by C. MacKensen. Karger: Basel.

Kolker, A. E., and Hetherington, J. (1976). In BeckerShaffer's Diagnosis and Therapy of the Glaucomas, p. 276. Mosby: St. Louis.

Luntz, M. H., and Livingston, D. G. (1977). Trabeculotomy $\mathrm{ab}$ externo and trabeculectomy in congenital and adult onset glaucoma. American Journal of Ophthalmology, 83, 174-179.

McPherson, S. D. (1973). Results of external trabeculotomy. American Journal of Ophthalmology, 76, 918-920.

Shields, M. B., Bradbury, M. J., Shelburne, J. D., and Bell, S. W. (1977). The permeability of the outer layers of limbus and anterior sclera. Investigative Ophthalmology, $16,866-869$.

Smith, R. (1960). A new technique for opening the canal of Schlemm. British Journal of Ophthalmology, 44, 370-373. 